\title{
Effects of Immunosuppressants on Platelet-Derived Growth Factor-A Chain mRNA Expression and Coronary Arteriosclerosis in Rat Cardiac Allografts
}

\author{
Mitsuhiro Hachida, MD; Xi-long Zhang, MD; Hua Lu, MD; \\ Hironobu Hoshi, MD; Hitoshi Koyanagi, MD
}

\begin{abstract}
Graft coronary arteriosclerosis (GCA) that results in proliferative and obstructive lesions limits the long-term success of cardiac transplantation. Despite extensive study, the pathogenic mechanisms underlying GCA are still unclear and therapeutic strategies for this condition have been inadequate. In this study, we compared the therapeutic effectiveness of cyclosporine A (CsA), 15-deoxyspergualin (DSG), and Multiglycosidorum tripterygii (MT) on GCA. In addition, we studied the correlation between the extent of GCA and the degree of plateletderived growth facter (PDGF)-A chain mRNA expression in cardiac grafts. Lewis rats receiving heterotropic heart transplants from Wistar King donors were treated with $10 \mathrm{mg} \mathrm{kg}^{-1}$ day $^{-1}$ of CsA (n=7), $5 \mathrm{mg} \mathrm{kg}^{-1} \mathrm{day}^{-1} \mathrm{of}^{-}$ DSG $(n=7)$ or $30 \mathrm{mg} \mathrm{kg}^{-1}$ day $^{-1}$ of MT $(n=7)$ respectively. Histological evaluation of coronary arteriosclerosis and Northern blot analysis of cardiac allograft PDGF-A chain mRNA expression were conducted on day 60 after transplantation. Varying levels of GCA were observed in the 21 transplanted hearts. Significant differences in both the degree of PDGF-A mRNA expression and the extent of GCA were found among the 3 groups. GCA was significantly reduced in allografts treated with MT or DSG in comparison with the level seen in CsA-treated grafts. A significant correlation was found between PDGF-A chain mRNA expression and the grade of arterial intimal thickening $(r=0.76, p<0.05)$ as well as with the incidence of diseased vessels $(r=0.82, p<0.01)$. Our results indicate that both MT and DSG are more effective in the treatment of GCA than CsA. In our cardiac allografts, the degree of PDGF-A chain mRNA expression correlated well with the extent of GCA, suggesting that PDGF-A may play an important role in the development of transplant-related GCA. (Jpn Circ J 1999; 63: 303-308)
\end{abstract}

Key Words: Coronary arteriosclerosis; Heart transplantation; Immunosuppressant; Platelet-derived growth factor

$\mathbf{G}$ raft coronary arteriosclerosis (GCA) is the major determinant of long-term survival after heart transplantation. Despite extensive research, the etiological and pathogenic mechanisms underlying the development of GCA are still unclear. Therapeutic strategies for this condition are still inadequate. Cyclosporine (CsA) has greatly improved the actuarial survival rate of heart transplant recipients. However, it has not been shown to decrease the incidence or the extent of GCA! Moreover, it has been suggested that longterm treatment with CsA may be a risk factor for GCA, ${ }^{2,3}$ There is therefore a need for promising new immunosuppressants.

Intimal and medial proliferation of smooth muscle cells (SMCs) plays an important role in the development of GCA. Enhanced expression of platelet-derived growth factor (PDGF) has been observed in cardiac allografts, and an involvement of PDGF in the occurrence of GCA has been speculated.,5 PDGF is a potent mitogen for vascular SMCs, and has been implicated as a cofactor in the pathogenesis of native atherosclerosis 6,7 It is composed of 2 closely related but nonidentical protein subunits, a PDGF-

(Received May 29, 1998; revised manuscript received December 16, 1998; accepted January 8, 1999)

Department of Cardiovascular Surgery, The Heart Institute of Japan, Tokyo Women's Medical College, Tokyo, Japan

Mailing address: Mitsuhiro Hachida, MD, Department of Cardiovascular Surgery, Heart Institute of Japan, Tokyo Women's Medical College, 8-1, Kawada-cho, Shinjuku-ku, Tokyo 162, Japan. E-mail: shachida@hij.twmc.ac.jp
A chain and a PDGF-B chain, which form 3 possible configurations: $\mathrm{AA}, \mathrm{AB}$, and $\mathrm{BB}$. It has been suggested recently that PDGF-AA may play a major role in the development of intimal lesions in GCA?

In the present study, 2 new immunosuppressants, Multiglycosidorum tripterygii (MT) and 15-deoxyspergualin (DSG) were evaluated for their effects on GCA in comparison to CsA. To clarify the contribution of PDGF to the development of GCA, we also investigated the correlation between the extent of GCA and the degree of PDGF-A chain mRNA expression in cardiac grafts.

\section{Materials and Methods}

Animals and Treatment

Male Wistar (RT-1 $\left.{ }^{\mathrm{k}}\right)$ and Lewis $\left(\mathrm{RT} 1^{1}\right)$ rats, weighing 200-240 g, were used as donors and recipients, respectively. All animals received care in compliance with the "Principles of Laboratory Animal Care" formulated by the Institute of Animal Resources, and the "Guide for the Care and Use of Laboratory Animals" prepared by the National Academy of Sciences and published by the National Institutes of Health (NIH Publication No. 86-23, revised 1985). Heterotopic heart transplantation was performed with a modification of the procedure described by Ono and Lindsey? After transplantation, the recipient rats received 60 days of immunosuppressive therapy after being randomly assigned to one of 3 groups of 7 rats each: (1) CsA group: CsA $10 \mathrm{mg} \mathrm{kg}^{-1}$ day $^{-1}$; (2) MT group: MT $30 \mathrm{mg} \mathrm{kg}^{-1} \mathrm{day}^{-1}$; 
Table 1 Morphometric Parameters

\begin{tabular}{lccc}
\hline \hline & MT group & DSG group & CsAgroup \\
\hline Rejection grade & $1.1 \pm 0.4$ & $1.1 \pm 0.4$ & $1.2 \pm 0.3$ \\
Incidence of diseased vessels $(\%)$ & $29.5 \pm 7.8^{* *}$ & $48.5 \pm 12^{*}$ & $69.1 \pm 11$ \\
Grade of arterial intimal thickening & $1.12 \pm 0.31^{*}$ & $1.21 \pm 0.22^{*}$ & $1.72 \pm 0.28$
\end{tabular}

MT, Multiglycosidorum tripterygii; DSG, 15-deoxyspergualin; CsA, Cycloporine A; *p<0.05 vs CsA group; ${ }^{*} p<0.05$ vs DSG group.
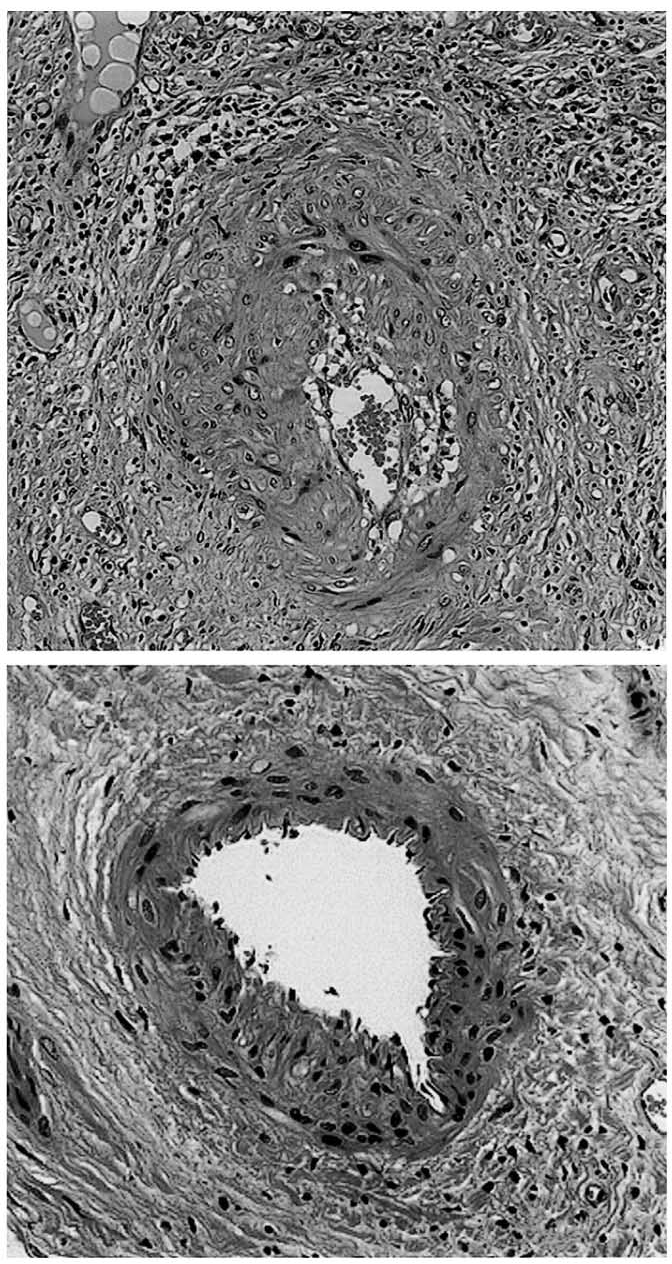

and (3) DSG group: DSG $5 \mathrm{mg} \mathrm{kg}^{-1} \mathrm{day}^{-1}$. CsA and DSG were administered intraperitoneally and MT was given by gavage. Post-transplant graft function was evaluated daily by palpation. Recipients with nonbeating heterografts were excluded from the study. The transplanted allografts were harvested on day 60 after transplantation.

\section{Histopathologic Processing}

Harvested grafts were bisected through the midportion of both ventricles before fixation in $10 \%$ formalin. The specimens were then embedded in paraffin and stained with hematoxylin and eosin to assess the severity of rejection, or with the Elastica Masson stain to assess coronary arterial intimal thickening. Rejection severity was graded on a scale of 0 (none) to 3 (severe), according to the grading system of Lurie et al $1^{10}$ In each section, all coronary arteries with a diameter of more than $50 \mu \mathrm{m}$ were studied, and the extent of coronary arterial intimal thickening was classified on a scale of 0 (normal) to 4 (occluded). The grade of arter-
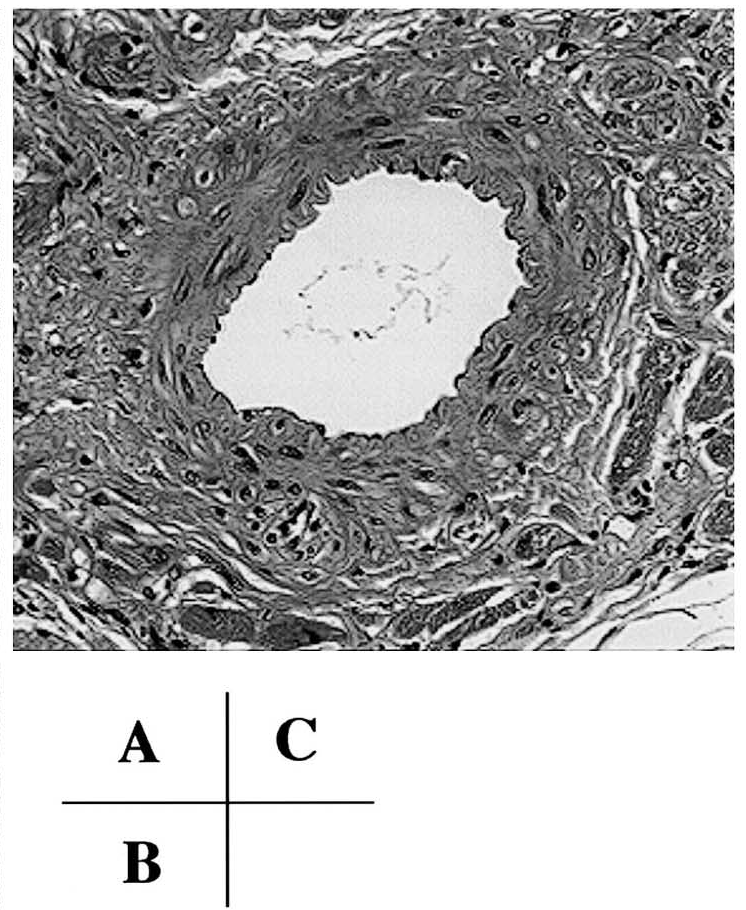

Fig 1. (A) Section of intramyocardial coronary artery in a CsA-treated graft, showing marked myointimal proliferation and luminal narrowing. (B) Section of intramyocardial coronary artery in a DSG-treated graft, showing smooth muscle proliferation and minor intimal thickening and luminal stenosis. (C) Section of intramyocardial coronary artery in a MT-treated graft with mild smooth muscle proliferation and minor intimal thickening and luminal stenosis.

ial intimal thickening was then calculated by the following formula:

Grade of arterial intimal thickening $=$

$$
\frac{\left(1 \times \mathrm{N}_{1}\right)+\left(2 \times \mathrm{N}_{2}\right)+\left(3 \times \mathrm{N}_{3}\right)+\left(4 \times \mathrm{N}_{4}\right)}{\mathrm{N}_{0}+\mathrm{N}_{1}+\mathrm{N}_{2}+\mathrm{N}_{3}+\mathrm{N}_{4}}
$$

where $\mathrm{Nn}$ is the number of vessels of classification $\mathrm{n}^{11}$

\section{PDGF-A mRNA Analysis}

The analysis of PDGF-A mRNA expression in graft myocardia was conducted by Northern blotting, using the technique described by Saiki and Oana et al12,13

\section{RNA Isolation}

After harvesting, the transplanted and native hearts were quickly frozen in liquid nitrogen and then stored at $-80^{\circ} \mathrm{C}$ until required for RNA isolation. Total RNA was isolated 
a

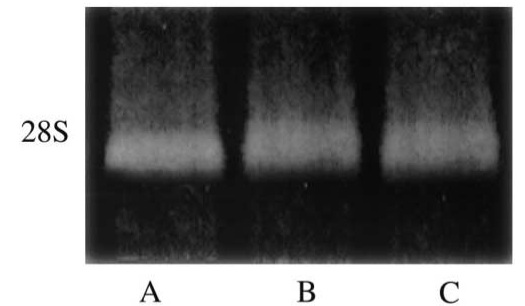

b

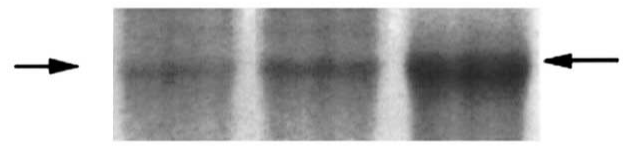

A

B

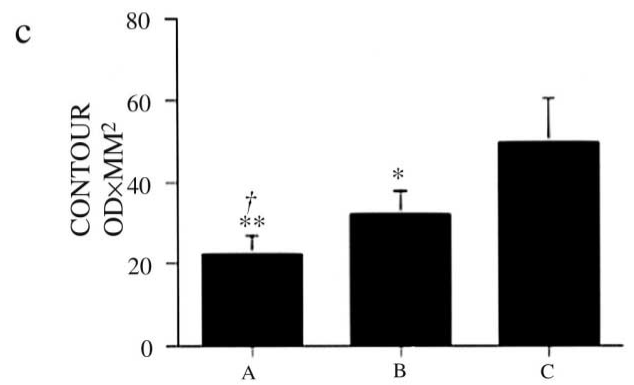

Fig 2. Northern blot analysis of myocardial PDGF-A chain mRNA expression from transplanted hearts. (Lane A) MT-treated group; (Lane B) DSG-treated group; (Lane C) CsA-treated group. Ten micrograms of total RNA from the myocardium was size-fractionated on a $0.8 \%$ denaturing agarose gel, transferred to a nylon membrane filter, and hybridized to an $\left[\mathrm{a}-{ }^{32} \mathrm{P}\right]-\mathrm{dCTP}-\mathrm{labeled}$ cDNA probe (A). The arrows indicate the position of PDGF-A chain mRNA. The intensities of the hybridization signals (A) were adjusted by estimating and normalizing to the OD of the 28S ribosomal RNA using an Image Master. (B). The adjusted results showed a significant decrease in PDGF-A chain mRNA expression in the MT- and DSG-treated groups in comparison to the CsA-treated group (25.4 \pm 6.2 and $39.8 \pm 9.4$ vs $62.2 \pm 12.9$. $\mathrm{p}<0.05)$.

and purified using RNA zol according to the manufacturer's protocol (Biotex Laboratories, Houston, TX).

\section{cDNA Probes and Polymerase Chain Reaction (PCR)}

To detect PDGF-A mRNA, an 826 bp cDNA fragment was generated by PCR from the total RNA isolated from rat heart grafts using 2 oligonucleotide primers. The primers were based on the rat PDGF-A sequence:

\section{1 (forward):}

\section{5'-GACCGCGGCCTCGCCTCCCTGCCGAGCTTCC-3'}

\section{2 (reverse):}

\section{5'-GACCGCGGTCTCGAGTGCTACAGTACTGC-3'}

Ten micrograms of total RNA was used for doublestrand cDNA synthesis using cDNA synthesis kits (Amersham, Bucks, UK). PCR reactions were performed at $\mathrm{pH} 8.3$ in $10 \mathrm{mmol} / \mathrm{L} \mathrm{Tris} / \mathrm{HCl}, 50 \mathrm{mmol} / \mathrm{L} \mathrm{KCl}, 1.5 \mathrm{mmol} / \mathrm{L}$ $\mathrm{MgCl}_{2}, 0.2 \mathrm{mmol} / \mathrm{L} \mathrm{dNTP}$, and $2 \mathrm{U}$ Taq polymerase. PCR amplification products were generated using a DNA thermal cycler for 35 cycles, comprising denaturing at $94^{\circ} \mathrm{C}$ for $45 \mathrm{~s}$, annealing at $55^{\circ} \mathrm{C}$ for $1 \mathrm{~min}$, and extension at $72^{\circ} \mathrm{C}$ for $90 \mathrm{~s}$ each cycle. The resulting $826 \mathrm{bp}$ cDNA fragment was subcloned into the polylinker region of pBluescript II SK(+). The nucleotide sequence was determined by the dideoxy chain termination method, analyzed by Genetics Gene Analysis System software (Genetics, Tokyo, Japan) and found to be identical to the previously reported rat PDGF-A sequence.

\section{Northern Blot Analysis}

Total RNA (10 $\mathrm{g}$ ) was denatured at $65^{\circ} \mathrm{C}$ for $2 \mathrm{~min}$, fractionated by electrophoresis in $1 \%$ agarose gels containing formaldehyde, and transferred to nylon membranes (Zeta-Probe Blotting Membranes, Bio-Rad) by blotting. Hybridization was performed at $65^{\circ} \mathrm{C}$ in a buffer containing $0.5 \%$ sodium dodecyl sulfate (SDS), $5 \times$ Denhardt's solution, $10 \%$ dextran sulfate, $5 \times \mathrm{SSC}$, and $50 \mu \mathrm{g}$ of salmon sperm DNA per $\mathrm{ml}$, followed by serial washing with a final wash in $0.1 \times \mathrm{SSC} / 0.1 \% \mathrm{SDS}$ at $65^{\circ} \mathrm{C}$. The probe was labeled with [a -32P]-dCTP (Amersham) using a nick translation labeling kit (Boehringer Mannheim, Germany). The intensity of the hybridization signal was determined by photostimulated luminescence using an image analyzer (BAS 2000, Fuji, Tokyo).

\section{Statistical Analysis}

All numerical data are expressed as mean \pm SE. The Kruskal-Wallis test ( $\mathrm{Z}$ corrected for ties) was used to evaluate difference between the 3 groups. A p value of less than 0.05 was regarded as statistically significant. Correlation coefficients were calculated by Spearman's nonparametric rank test in which "rs" means the correlation coefficiency.

\section{Results}

Histopathologic examination revealed prominent luminal narrowing in most of the grafts in the CsA-treated group, with intimal and myointimal proliferation (Fig 1A). In contrast, only moderate narrowing was found in the DSGtreated group (Fig 1B), and narrowing was seen rarely in the MT-treated group (Fig 1C).

The morphometric results from all 21 rats are summarized in Table 1. There were no significant differences in the grade of rejection between the 3 groups. The calculated incidence of diseased vessels (IDV) was found to be lowest in the MT group and highest in the CsA group. There was a significant difference in IDV between the CsA and MT groups, and the CsA and DSG groups. Furthermore, we found a significant difference in IDV between the MT and DSG groups. The grade of arterial intimal thickening was found to be significantly less in the MT and DSG groups than in the CsA group. No significant difference in the grade of arterial intimal thickening was found between the MT- and DSG-treated grafts.

PDGF-A chain mRNA expression is shown in Fig 2. The level of PDGF-A mRNA in cardiac grafts was significantly lessened by treatment with MT or DSG compared to treatment with CsA.

According to correlation analysis, the degree of PDGFA mRNA expression was found to correlate significantly with IDV (Fig 3 ). In addition, a positive correlation was found between the degree of PDGF-A mRNA expression and the grade of arterial intimal thickening (Fig 4). No correlation was demonstrated between rejection grade and IDV, the grade of arterial intimal thickening, or the degree of PDGF-A mRNA expression. These results suggest that 


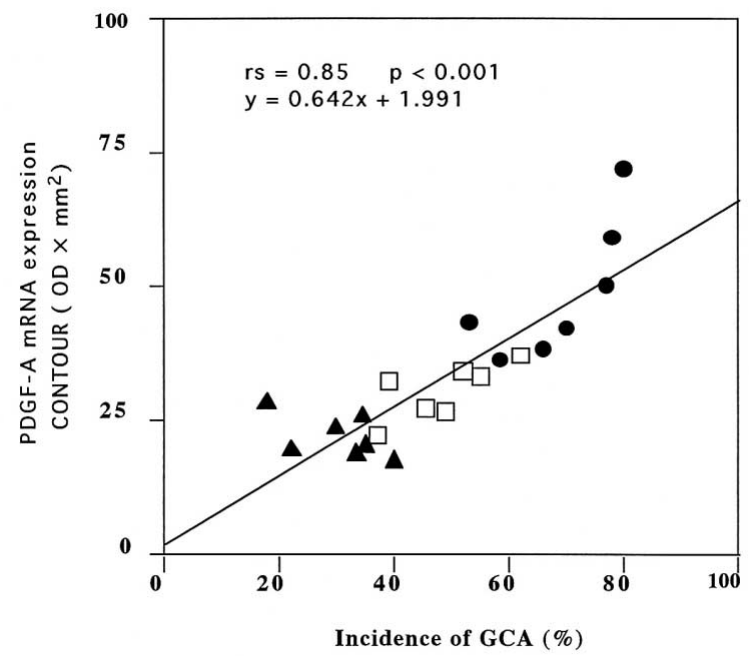

Fig 3. Correlation of PDGF-A mRNA expression with the incidence of diseased coronary vessels in cardiac allografts. PDGF-A mRNA expression was measured by Northern blot analysis. $\mathrm{OD} \times \mathrm{mm}^{2}$ indicates the adjusted signal intensity of PDGF-A mRNA to the OD of the 28S ribosomal RNA. (๑) CsA-treated group; ( $\square$ ) DSG-treated group; ( $\mathbf{\Lambda})$ MT-treated group.

PDGF-A mRNA expression is associated with the extent of GCA in cardiac grafts.

\section{Discussion}

Transplant-derived GCA represents one of the major barriers to longterm survival of cardiac transplant recipients. The incidence of this condition varies from $25 \%$ to $80 \%$ within the first 5 years $!^{14}$ The pathogenic mechanism of GCA is still unknown. Multiple factors are believed to be involved. Growth factors including PDGF, insulin-like growth factor-1, and fibroblast growth factor have been suggested to play a causal role in the development of GCA ${ }^{14}$ In the present study we focused on the correlation between PDGF-A chain mRNA expression and the extent of GCA in cardiac grafts, the therapeutic effects of 3 immunosuppressants and the effect of these immunosuppressants on the level of PDGF-A mRNA expression after heart transplantation.

The MT and DSG compounds used in this study are relatively new immunosuppressants. MT, also termed Tripterygium wilfordii, is extracted from the plant Tripterygium wilfordii Hook $\mathrm{F}$ and refined. It contains chiefly stable glycosides and has relatively few side effects. Li et al ${ }^{15}$ demonstrated that MT is capable of inhibiting several afferent immune functions including the response of human peripheral blood mononuclear cells to mitogens and alloantigens, and the generation of cytotoxic $\mathrm{T}$ cells. They suggest that this inhibition is likely mediated via a reduction in both IL-2 production and responsiveness by blocking DNA replication. We demonstrated previously that MT inhibits the extent of GCA significantly more than CsA 16 However, the exact mechanism underlying the effect of MT on GCA inhibition remains to be determined. Recently, our in vitro study showed that MT inhibited mixed lymphocyte reactions with a 50\% inhibition concentration 10 times lower than that of CsA. The mechanism underlying the immunosuppressive effect of MT appears to relate to its inhibition of the T-cell response to IL-2. However this needs to be confirmed. The effect of DSG on

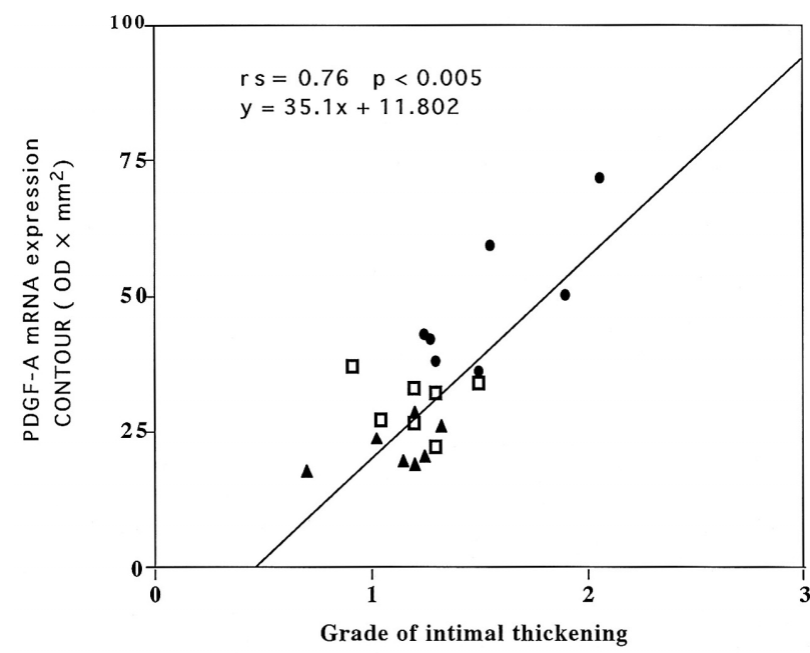

Fig 4. Correlation of PDGF-A mRNA expression with the grade of coronary arterial intimal thickening. PDGF-A mRNA expression was measured by Northern blot analysis. $\mathrm{OD} \times \mathrm{mm}^{2}$ indicates the adjusted signal intensity of PDGF-A mRNA to the OD of the $28 \mathrm{~S}$ ribosomal RNA. (•) Cs A-treated group; ( $\square$ ) DSG-treated group; (ム) MT-treate group.

the inhibition of GCA was first reported by Nagamine et al ${ }^{11}$ Zhang et al ${ }^{17}$ further showed that DSG may inhibit PDGF-A chain mRNA expression in rat cardiac allografts. The protective effects against GCA of DSG over those of CsA may result from its different immunosuppressive actions. CsA is known to suppress the immune system by inhibiting interleukin-2 production ${ }^{18}$ Its role in directly suppressing macrophage function and humoral immune responses remains controversial $!^{19,20}$ In contrast, DSG directly suppresses macrophage function, inhibiting the expression of HLA-DR antigens and the production of antibody? 1,22

PDGF is one of the best characterized mitogens for vessel wall cells. It is secreted by platelets, monocytes, macrophages, endothelial cells, vascular SMCs and other cell types ${ }^{23}$ PDGF has been implicated as an important growth factor contributing to the pathophysiology of arteriosclerosis and chronic inflammation-derived tissue remodeling. Shaddy et $\mathrm{al}^{5}$ reported that PDGF expression was increased during vascular rejection, suggesting a potential correlation between vascular rejection and increased PDGF synthesis. Transplant-derived immune injury to endothelial cells may increase the expression of adhesion molecules by T-lymphocytes and monocytes/macrophages, causing activation of cytokine cascades and the release of growth factors including PDGF. These growth factors, expressed in SMCs and endothelial cells, act as autocrine and/or paracrine growth regulators to accelerate the proliferation of blood vessel SMCs? ${ }^{24}$ In cardiac grafts undergoing chronic rejection, Lemstrom et $\mathrm{al}^{8}$ suggested that continuous low-grade immunological damage and inflammatory responses may also be related to the release of cytokines and growth factors from these cells, resulting in the migration of SMCs from the media and their proliferation in the intima followed by intimal thickening. Furthermore, they demonstrated that high-dose CsA treatment concomitantly results in a significant reduction in PDGF-AA and PDGF receptor-a expression in intimal cells and intimal thickening compared with low-dose CsA treatment. In transplanted hearts, Saito et al ${ }^{25}$ demonstrated that PDGF is 
localized mainly in the intimal layer of graft vessels.

GCA may result in severe obstruction in the allograft vessels that could eventually lead to deterioration in graft function. GCA differs in its pathohistological characteristics from age-related coronary atherosclerosis. In GCA, the lesion appears to be diffuse and concentric, affecting the entire length of the vessel of all coronary arteries in the transplanted heart. The internal elastic lamina also remains intact, calcification is rare, and the disease tends to develop rapidly?26,27 Studies of GCA have been focused on (1) a better understanding of pathologic mechanisms underlying the development of GCA, (2) an effective therapeutic strategy for this irreversible condition, and (3) attempting to determine some predictors which can be used to monitor the development of GCA or the efficacy of treatment.

In the present study, we used cDNA probes complementary to the PDGF-A chain mRNA to identify the corresponding steady-state expression of PDGF-A mRNA in rat cardiac grafts. We found that there is a significant association between PDGF-A mRNA expression and the extent of GCA. This finding supports the theory that PDGF-A plays an important role in the pathogenesis of GCA. It also suggests that the level of PDGF-A chain mRNA may serve as a predictor in monitoring GCA development or in judging the efficacy of GCA treatment. Consistent with our observations is the finding that after heart transplantation the increased expression of PDGF is further increased following infection with cytomegalovirus, which may also potentially accelerate GCA.28,29

An important question remains whether the increase in the expression of PDGF-A chain mRNA observed in the present study is the cause of or result of GCA. The current study does not answer this question, as we did not observe the expression of PDGF-B and other growth factors that are thought to be involved in the development of GCA30 Further studies on these issues are needed to clarify possible mechanisms underlying the effects of PDGF-A and other growth factors on cardiac grafts.

In conclusion, the new immunosuppressants MT and DSG are more effective than CsA in the attenuation of post-transplantation GCA. The effects of these 2 agents on GCA correlate with their effects on the inhibition of PDGF, and PDGF-A chain mRNA expression correlates well with the extent of GCA 2 months after heart transplantation. This suggests that PDGF-A may play an important role in the development of GCA. Thus it may be of clinical importance to inhibit the expression of PDGF-A in order to prevent the subsequent occurrence of GCA.

\section{References}

1. Uretsky BF, Murali S, Reddy PS et al: Development of coronary disease in cardiac transplant recipients receiving immunosuppressive therapy with cyclosporine A and prednisone. Circulation 1987; 76: 827-834

2. Haverich A, Costard-Jackle A, Cremer J et al: Cyclosporine A and transplant coronary disease after heart transplantation: Facts and Fiction. Transplant Proc 1994; 26: 2713-2715

3. Paul LC, Davidoff A, Benediktsson H: Cardiac allograft atherosclerosis in the rat. The effect of histocompatibility factors, cyclosporine, and an angiotensin-converting enzyme inhibitor. Transplantation 1994; 57: $1767-1772$

4. Zhao XM, Yeoh TK, Frist WH, Porterfield DL, Miller GG: Induction of acidic fibroblast growth factor and full-length platelet-derived growth factor expression in human cardiac allografts. Circulation 1994; 90: 677-685

5. Shaddy RE, Hammond EH, Yowell RL: Immunohistochemical analysis of platelet-derived growth factor and basic fibroblast growth factor in cardiac biopsy and autopsy specimens of heart transplant patients. Am J Cardiol 1996; 77: 1210-1215

6. Barrett TB, Benditt EP: Platelet-derived growth factor gene expression in human atherosclerotic plaques and normal artery wall. Proc Natl Acad Sci USA 1988; 85: 2810-2814

7. Wilcox JN, Smith KM, Williams LT, Schwartz SM, Gordon D: Platelet-derived growth factor mRNA detection in human atherosclerosis plaques by in situ hybridization. J Clin Invest 1988; 82: 1134 1143

8. Lemstrom KB, Koskinen PK: Expression and localization of platelet-derived growth factor ligand and receptor protein during acute and chronic rejection of rat cardiac allografts. Circulation 1997; 96: $1240-1249$

9. Ono K, Lindsey ES: Improved technique of heart transplantation in rats. J Thorac Cardiovasc Surg 1969; 57: 225-229

10. Lurie KG, Billingham ME, Jamieson SW, Harrison DC, Reitz BA: Pathogenesis and prevention of graft arteriosclerosis in an experimental heart transplantation model. Transplantation 1981; 31: 41 47

11. Nagamine S, Ohmi M, Tabayashi K, Iguchi A, Mohri H: Effects of cyclosporine and 15-deoxyspergualin on coronary arteriosclerosis after heart transplantation in rat. J Heart Lung Transplant 1994; 13: 895-898

12. Saiki RK, Gelfand DH, Stoffel S, Scharf SJ, Higuchi R, Horn GT, et al: Primer-directed enzymatic amplification of DNA with a thermostable DNA polymerase. Science 1988; 239: 487-491

13. Oana S, Matsuoka R, Nakajima H, Hiratsuka E, Furutani Y, Takao A, et al: Molecular characterization of a novel atrial-specific myosin heavy-chain gene expressed in the chick embryo. Eur J Cell Biol 1995; 61: 42-49

14. Wahlers T, Mugge A, Oppelt P, Heublein B, Fieguth HG, Jurmann MJ, et al: Preventive treatment of coronary vasculopathy in heart transplantation by inhibition of small muscle cell proliferation with angiopeptin. J Heart Lung Transplant 1995; 14: 143-150

15. Li XW, Weir M: Radix tripterygium wilfordii - a chinese herbal medicine with potent immunosuppressive properties. Transplantation 1990; 50: 82

16. Hachida M, Zhang XL, Lu H, Hoshi H, Koyanagi H: Inhibitory effect of Multiglycosidorum tripterygium on coronary arteriosclerosis after heart transplantation. Transplantation 1998; 65: 1446-1450

17. Zhang XL, Hachida M, Lu H, Furukawa H, Hoshi H, Koyanagi H: Effect of 15-deoxyspergualin on coronary arteriosclerosis and platelet-derived growth factor-A mRNA expression in the transplanted heart. J Tokyo Wom Med Coll 1998; 68: 66-72

18. Kronke M, Leonard WJ, Depper JM, et al: Cyclosporine inhibits Tcell growth factor gene expression at the level of mRNA transcription. Proc Natl Acad Sci USA 1984; 80: 5214-5218

19. Palay DA, Cluff CW, Wentworth PA, et al: Cyclosporine inhibits macrophage-mediated antigen presentation. J Immunol 1986; 136: $4348-4353$

20. Snyder DS, Wright CL, Ting C: Inhibition of human monocyte antigen presentation, but not HLA-DR expression by cyclosporine. Transplantation 1987; 44: 407-411

21. Fujii H, Takada T, Nemoto K, et al: Deoxyspergualin directly suppresses antibody formation in vivo and in vitro. J Antibiot 1990; 43: $213-219$

22. Dickneite G, Schorlemmer HU, Sedlacek HH, et al: Suppression of macrophage function and prolongation of graft survival by the new guanidinic-like structure, 15-deoxyspergualin. Transplant Proc 1987; 19: $1301-1304$

23. Higgy NA, Davidoff AW, Grothman GT, Hollenberg M, Benediktsson H, Paul LC: Expression of platelet-derived growth factor receptor in rat heart allografts. J Heart Lung Transplant 1991; 10: $1012-1022$

24. Vuillemin T, Legendre C, Meduri G, Larue JR, Goupy C, Kriaa F, et al: Chronic rejection and cell growth factor. Transplant Proc 1996; 28: $2831-2832$

25. Saito S, Motomura N, Lou H, Ramwell P, Foegh M: Specific Effect of estrogen on growth factor and major histocompatibility complex class II antigen expression in rat aortic allograft. J Thorac Cardiovasc Surg 1997; 114: 803-810

26. Meiser BM, Wenke J, Thiery SW, Wolf S, Devens C, Seidel D, et al: Simvastatin decreases accelerated graft vessel disease after heart transplantation in an animal model. Transplant Proc 1993; 25: 2077-2079

27. Ventura HO, Mehra MR, Smart FW, Stapleton DD: Cardiac allograft vasculopathy: current concepts. Am Heart J 1995; 129: 791 - 799

28. Lemstrom K, Koskinen P, Bruning H, Bruggeman C, Aho P, Hayry $P$ : Cytomegalovirus infection accelerates mRNA expression of several smooth muscle cell growth factors in the allograft vascular 
wall. Transplant Proc 1995; 27: 566-567

29. Hatanaga M, Omoto R: The promoting effect of cytomegalovirus on coronary arteriosclerosis of transplanted hearts. Transplantation 1993; 28: $286-288$
30. Lou H, Kodama T, Zhao YJ, Maurice P, Wang YN, Katz N, et al: Inhibition of transplant coronary arteriosclerosis in rabbits by chronic estradiol treatment is associated with abolition of MHC class II antigen expression. Circulation 1996; 94: 3355-3361 